\title{
DÜBLIN
}

Technological University Dublin

ARROW@TU Dublin

1998-01-01

\section{Electroanalysis Using Differential Pulse Methods at a Microelectrode}

\author{
Enda Howard \\ Technological University Dublin \\ John Cassidy \\ Technological University Dublin, john.cassidy@tudublin.ie \\ John O'Gorman \\ Technological University Dublin
}

Follow this and additional works at: https://arrow.tudublin.ie/scschcpsart

Part of the Chemistry Commons

\section{Recommended Citation Microelectrode. Electroanalysis, Vol. 10, 1998, pp.1208-1210. \\ This Article is brought to you for free and open access by the School of Chemical and Pharmaceutical Sciences at ARROW@TU Dublin. It has been accepted for inclusion in Articles by an authorized administrator of ARROW@TU \\ Dublin. For more information, please contact \\ arrow.admin@tudublin.ie, aisling.coyne@tudublin.ie, gerard.connolly@tudublin.ie. \\ Funder: Technological University Dublin SRD grant}

Howard, E., Cassidy, J.F., O'Gorman, J.:Electroanalysis Using Differential Pulse Methods at a

doi:10.1002/(SICI)1521-4109(199811)10:17<1208::AID-ELAN1208>3.0.CO;2-V

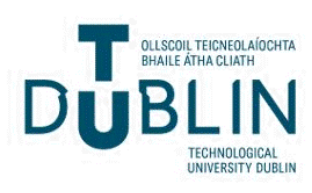




\title{
Short Communication
}

\section{Electroanalysis Using Differential Pulse Methods at a Microelectrode}

\author{
Enda Howard, John F. Cassidy, * and John O'Gorman
}

School of Chemistry, Dublin Institute of Technology, Kevin Street, Dublin 8, Ireland

Received: June 1, 1998

Final version: August 10, 1998

\begin{abstract}
Keywords: Microelectrodes, Differential pulse voltammetry
\end{abstract}

This communication characterises the differential pulse voltammetric response of ultramicroelectrodes in connection wich two different models

Microelectrodes have been cited to have many advantages over convencional electrodes [1-3]. However, a primary disadvantage is that the use of a microelectrode in a potential sweep mode results in a sigmoidal output which is difficult to interpret at low analyte concentrations. The aim of this work is to characterize the differential current response of a microelectrode. This may be done by numerical differentiation of a digitally acquired signal following a linear sweep which is trivial [4], or through the use of an applied differential pulse waveform.

The following assumptions were made in postulating the theory for differential pulse voltammetry at a planar disk microelectrode [5] and are the basis for Model 1.

a) The Cottrell equation may be used for characterization of the current response at short time periods following the pulse.

b) The current due to the potential ramp follows the traditional microelectrode behavior with a potential dependent component.

c) The above two currents, a) and b), are additive for an electrochemically reversible reduction, thus

$$
i_{1}=\frac{n F A C \sqrt{D}}{\sqrt{\pi \delta}}\left[\frac{\left.1-\sigma^{2}\right) \epsilon_{1}}{\left(1+\epsilon_{1}\right)\left(1+\sigma^{2} \epsilon_{1}\right)}\right]
$$

where

$$
\begin{aligned}
\sigma^{2} & =\exp \left(\frac{n F \Delta E}{R T}\right) \\
i_{2} & =\frac{4 n F r D C}{1+\epsilon_{1}}
\end{aligned}
$$

where

$$
\begin{aligned}
& \epsilon_{1}=\exp \left(\frac{n F\left(E_{1}-E^{\alpha}\right)}{R T}\right) \\
& i_{3}=\frac{4 n F r D C}{1+\epsilon_{2}}
\end{aligned}
$$

where

$$
\epsilon_{2}=\exp \left(\frac{n F\left(E_{2}-E^{0^{\prime}}\right)}{R T}\right)
$$

Where $i_{1}$ is the current contribution from the pulse alone, $i_{2}$ is the current due to the potential ramp before the pulse is applied, taking the limiting steady-state current to be

$$
i_{\mathrm{L}}=4 n F r D C
$$

where $r$ is the electrode radius, $n$ is the number of electrons involved, $F$ is the Faraday constant and $D$ and $C$ are the diffusion coefficient and the concentration of the electroactive species. $i_{3}$ is the current due to the potencial ramp at a time $(\delta+\tau)$, if the pulse was not applied. $E_{1}$ is the potential prior to pulse (at a time $\tau$ ), $E_{2}$ is the potential defined by the potential ramp if the pulse was not applied (at a time $\delta+\tau$ ). $\tau$ is the time at which the current is sampled before the pulse is applied and $(\hat{o}+\tau)$ is the time at which the current is sampled after the pulse is applied. $\Delta E$ is the pulse amplitude and all other symbols have their usual meaning. The instrumental differential output is represented as follows by the sum of the current due to the underlying ramp at time $(\delta+\tau), i_{3}$, and the current due to the pulse $i_{1}$. less the current before the pulse $i_{2}$.

$$
\delta i=i_{1}+i_{3}-i_{2}
$$

In practice during the timescale of the experiment the diffusion layer thickness was found to be of the same order of magnitude as the diameter of the microelectrode. This facilitated the presence of "edge effects" which leads to a steady-state current being reached within the pulse width $(\delta)$. By modifying the theory the differentiai current may be calculated as follows using Model 2.

$$
\delta i^{*}=i_{4}-i_{2}
$$

where

$$
i_{4}=\frac{4 n F r D C}{1+\epsilon_{3}}
$$

and

$$
\epsilon_{3}=\exp \left(\frac{n F\left(E_{2}+\Delta E-E^{\sigma^{\prime}}\right)}{R T}\right)
$$

where $i_{4}$ is the steady-state current following the pulse and $i_{2}$ is the current due to the ramp potential before the pulse is applied. This modified theory allows for steady-state current to occur before and after the pulse.

From the limiting current $\left(i_{\mathrm{L}}\right)$ of the voltammetric response oblained by scanning the potential of a platinum microelectrode in a solution of $5 \times 10^{-3} \mathrm{M}$ ferrocyanide in a solution of $0.1 \mathrm{M} \mathrm{KCl}$, the electrode radius was found from Equation 7 . Taking $i_{\mathrm{L}}$ to be $5.60 \times 10^{-9} \mathrm{~A}$, and the diffusion coefficent $(D)$ for $\left[\mathrm{Fe}(\mathrm{CN})_{6}\right]^{4-}$ to be $6.5 \times 10^{-6} \mathrm{~cm}^{2} \mathrm{~s}^{-1}[6]$ the electrode radius $(r)$ was calculated as $4.46 \times \times 10^{-6} \mathrm{~m}$.

Figure 1 shows the response obtained by the application of a differential pulse waveform to a platinum microelectrode in a solution of $5 \mathrm{mM}\left[\mathrm{Fe}(\mathrm{CN})_{6}\right]^{4-}$. It can be seen that the peak current heights increase with increasing pulse amplitude but at the expense of return to baseline. Closer investigation revealed that the increase in peak current height was linear with pulse amplitude over a 


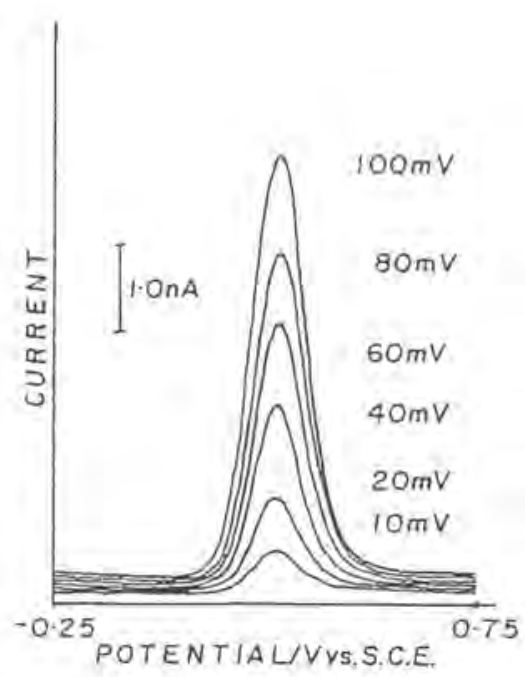

Fig. 1. Differential pulse output for a microelectrode in a solution of $5 \mathrm{mM}$ $\left[\mathrm{Fe}(\mathrm{CN})_{6}\right]^{4-}$ in $0.1 \mathrm{M} \mathrm{KCl}$. Instrumental time constant: $1 \mathrm{~s}$, sweep rate: $10 \mathrm{mV} / \mathrm{s}$. Differential pulse waveform period: $1.0 \mathrm{~s}$, puise width: $55 \times 10^{-3} \mathrm{~s}$. Pulse amplitudes are shown in the figure.

limited range. The effect of varying the differential pulse waveform period (taken here to be the time between pulse applications) was aiso investigated. It was found that long differential pulse waveform periods ( $>1.0 \mathrm{~s}$ ) resulted in stepped responses with ill-defined peaks while shorter differential pulse waveform periods resulted in smoother traces with well-defined peaks. The magnitude of the differential pulse waveform period was found to have negligable effect on peak current heights.

Figure 2 compares the experimental results obtained from the numerical derivative of a sigmoidal experimental plot, Figure $3 \mathrm{a}$. and the response from the application of a differential pulse waveform to the same electrode, Figure 2b. Also included are simulated plots using Equation 8, Figure 2c, and Equation 9. Figure 2d. It is immediately obvious that Model 1 (Eq. 8), does not

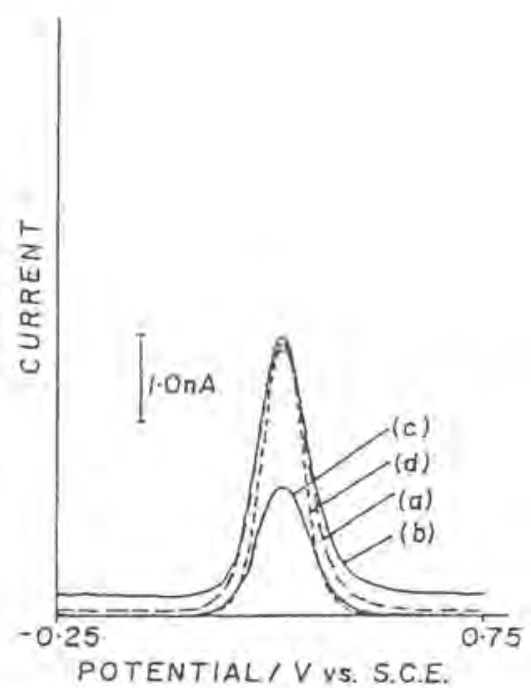

Fig. 2. a) Numerical point by point derivative of a linear sweep response for $5 \mathrm{mM}\left[\mathrm{Fe}(\mathrm{CN})_{6}\right]^{4-}$ in $0.1 \mathrm{M} \mathrm{KCl}$ at a microelectrode $\left(r=4.46 \times 10^{-6} \mathrm{~m}\right)$ where the sweep rate was $10 \mathrm{mV} / \mathrm{s}$. Points which gave a pulse height of $60 \mathrm{mV}$ were chosen. b) Experimental differential pulse output $(\Delta E=$ $60 \mathrm{mV}$ ), sweep rate: $10 \mathrm{mV} / \mathrm{s}$, time constant: $1 \mathrm{~s}$. c) Model 1, (Eq. 8) calculated using the parameters as above. d) Model 2 (Eq. 9) calculated using the parameters as above.
Table 1. Comparison of the various theoretical models with the experimental data. Conditions as in Figure?

\begin{tabular}{lllll}
\hline $\begin{array}{l}\text { Pulse } \\
\text { amplirude } \\
\text { [mV] }\end{array}$ & $\begin{array}{l}\text { Experimental } \\
\text { differential } \\
\text { pulse peak } \\
\text { height [nA] }\end{array}$ & $\begin{array}{l}\text { Peak heights } \\
\text { from } \\
\text { Model I } \\
\text { [nA] }\end{array}$ & $\begin{array}{l}\text { Peak heights } \\
\text { from } \\
\text { Model 2 } \\
\text { [nA] }\end{array}$ & $\begin{array}{l}\text { Numerical } \\
\text { derivative } \\
\text { peak heights } \\
\text { [nA] }\end{array}$ \\
\hline 100 & 4.98 & 1.45 & 4.29 & 4.23 \\
80 & 3.80 & 1.29 & 3.76 & 3.61 \\
60 & 2.98 & 1.05 & 3.05 & 2.90 \\
40 & 1.85 & 0.76 & 2.19 & 2.09 \\
20 & 0.65 & 0.43 & 1.14 & 1.09 \\
\hline
\end{tabular}

correlate well with either of the experimental traces whereas Model 2 (Eq. 9) correlates well with both experimental traces.

Table 1 lists the peak current heights corresponding to each of the experimental methods and simulations over a range of pulse amplitudes. In the case of the differential pulse waveform the correlation between experimental peak current heights and those predicted by Model 2 occurs only over a narrow pulse amplitude range. However it can be seen that the peak current heights obtained by numerically differentiating the sigmoidal experimental plot correlate well with those predicted by Model 2 over the complete range of pulse amplitudes studied. It is therefore possible to enjoy the advantage of a peaked response which is well-defined (Model 2) over a wide range of pulse amplitudes without having to invest in new and sophisticated equipment, the only system requirements being a linear ramp waveform generator, a data acquisition unit and a computer with relevant software, all of which are commonplace in any electrochemistry laboratory.

The results for peak current from Model 2 and peak current values from the numerical derivative of a linear sweep correlate well. The reason for slight differences may be because of the fast sweep rate used $(10 \mathrm{mV} / \mathrm{s})$. However the experimental differential puise response deviates from Model 2, indicating that there may be some contribution to the response from the pulse and that a steady state has not occurred in the timescale of the puise width. This may be due to slow electron transfer kinetics on such a short time scale or a combination of slow electron transfer kinetics and diffusion control.

As stated earlier Model 2 is based on the fact that a steady-state current is reached within the pulse width due to the presence of edge effects which in turn are due to the thickness of the diffusion layer being of the same order of magnitude as the electrode diameter. The diffusion layer thickness $(d)$ is approximated by the equation $d=(\pi D t)^{\frac{1}{2}}=1.06 \times 10^{-5} \mathrm{~m}$ where $t=$ pulse width $=55 \mathrm{~ms}$. Therefore the thickness of the diffusion layer $(d)$ is controlled by the pulse width $(t)$, and the diffusion coefficent $(D)$, both of which are constant for a given set of experimental conditions. It is clear that the extent to which Model 2 can be applied to a given experimental arrangement depends directly on the relative magnitudes of the electrode diameter and the diffusion layer thickness.

A distinct advantage of applying a differential pulse to a microelectrode can be seen at lower concentrations. This is evident in Figure 3 where the response is shown both for direct current and the differential current following the application of a differential pulse. The direct current response is very difficult to interpret and therefore almost useless in providing analytical information. However for the differential pulse response there is useful information to be gained as a peak is clearly seen at the potential at which the electrochemical reaction in question is known to occur. This has the effect of lowering the limits of detection relative to the direct current experiments. Also a peaked response is more desirable as a baseline can be drawn enabling peak current to be ensily 


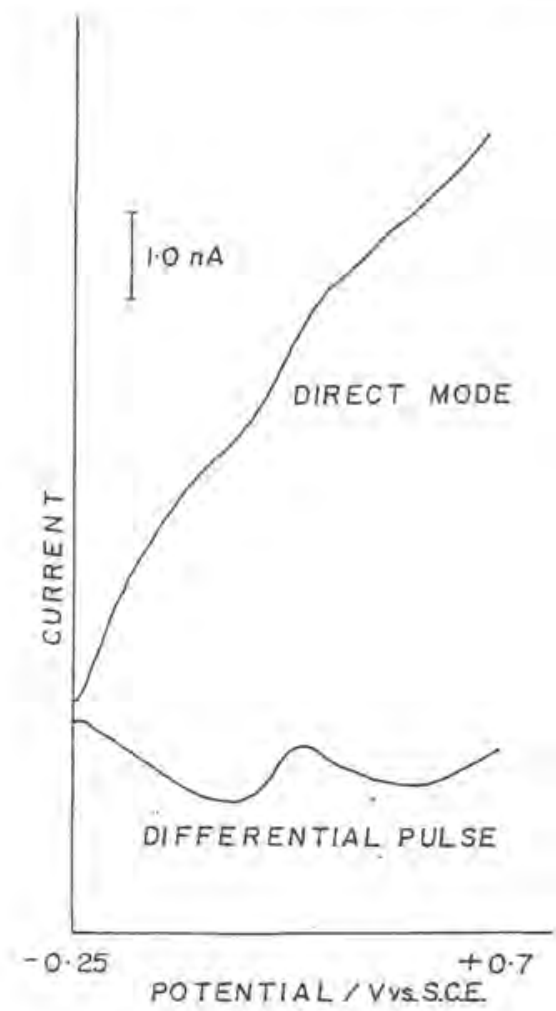

Fig. 3. Comparison of the responses produced by the application of a linear sweep and a differential pulse waveform at a micnoelectrode in a solution of $5 \mathrm{mM}\left[\mathrm{Fe}(\mathrm{CN})_{6}\right]^{2-}$ in $0.1 \mathrm{M} \mathrm{KCl}$. Platinum microelectrode of radius $4.46 \times 10^{-6} \mathrm{~m}$, scan rate in both cases was $10 \mathrm{mV} \mathrm{s}^{-1}$ and in the case of the differential pulse the time constanc. $1.0 \mathrm{~s}$, differential pulse waveform period: $1.0 \mathrm{~s}$, pulse width $=55 \times 10^{-3} \mathrm{~s}$ and the puise amplitude: $100 \mathrm{mV}$.

determined. This is in stark contrast to the difficulties encountered when attempting to measure limiting current from a direct curnent microelectrode experiment at submillimolar concentrations.
In conclusion, there is good correlation between Model 2 and the numerical derivative of a linear sweep potential waveform applied to a microelectrode. A differential pulse study does not correlate as well perhaps due to slow kinetics. Model 1 will apply for larger electrodes. Work on examining the effect of slow kinetics on the response is ongoing.

\section{Experimental}

The potentiostat used throughout this work was an Edr Model ECP 100 and a J.J. Lloyd $X-Y$ chart recorder Model PL 3 was used to chart the response. A three electrode system consisting of a carbon rod auxiliary, a saturated calomel reference electrode and an EG\&G Parc platinum planar disk microelectrode was employed. All chemicals used were of reagent grade and all solutions were made up using deionized water. Solutions were degassed by bubbling with nitrogen for at least 15 min prior to recording any data. A Pasco Scientific Cl-6510 analogue to digital converter was used to collect and store the data digitally and the simulations were carried out using a program written in Microsofit Excel.

\section{Acknowledgement}

Enda Howard would like to thank the Dublin Institute of Technology for an SRD grant.

\section{References}

[1] R.M. Wightman, D.O. Wipf, in Electroanalytical Chemistry, A Series of Advances Vol. 15 (Ed: A.J. Bard) Marcel Dekker, New York 1988.

[2] S. Pons, M. Fleischmann, Anal. Chem. 1987, 59, 1391A.

[3] R.M. Wightman, Science 1988, 240, 415 .

[4] D. Diamond, V.C. Hanratty, Spreadsheet Applications in Chemistry using Microsoft Excel, Wiley 1997.

[5] J.E. Anderson, A.M. Bond, R.D. Jones, Anal. Chem. 1981, 53, 1016.

[6] D.T. Sawyer, J.L. Roberts, Experimental Electrochemistry for Chemists, Wiliey, New York 1974, p.77. 